\title{
O labirinto finissecular e as idéias do esteta
}

\author{
Luiz Edmundo Bouças Coutinho e Irineu E. Jones (orgs.) \\ Rio de Janeiro: 7 Letras, 2004.
}

Porque recolhe e inscreve as idéias e as estéticas cujos roteiros engendram as últimas décadas dos séculos XIX e XX, O labirinto finissecular e as idéias do esteta é um livro que tem muito a ver com este início de milênio. Digo isso porque seus núcleos temáticos se bifurcam, se refletem, entre outros, nas formas e nos temas nossos de cada dia, sejam eles: a vertigem finissecular e o colapso das idéias, o decadentismo e os limites da modernidade, a influência do mercado nas produções culturais, nossa subjetividade maquínica, a releitura e os deslocamentos dos valores.

O livro se compõe de 16 ensaios críticos produzidos pelo Estéticas de fim-de-século, da Universidade Federal do Rio de Janeiro (Diretório dos Grupos de Pesquisa no Brasil/CNPq). Formado por professores de várias universidades brasileiras, escritores, tradutores e poetas, o grupo é liderado por Luiz Edmundo Bouças Coutinho, professor de Teoria Literária e Literatura Comparada da UFRJ. Ele apresenta o livro que organiza em parceira com Irineu Corrêa, pesquisador do referido grupo, e autor de longo ensaio que conecta os discursos da arte e da ciência. Nessa conexão, assinala as "apropriações poéticas" feitas pela psicanálise e destaca a crise do texto científico.

Incrustado no pórtico de O labirinto finissecular e as idéias do esteta, o ensaio de Latuf Isaías informa e seduz. Isso se dá principalmente por dois motivos: pelo repertório do autor e pela singularidade de sua escrita, que, a exemplo dos bons decadentistas, estetiza a própria informação - "Walter Horatio Pater \& a febre do esteticismo". Essa estetização textual aciona uma linguagem de tonalidade clara, levemente coloquial e gramaticalmente refinada (o verbo que abre este terceiro parágrafo é o mesmo utilizado pelo autor para iniciar seu texto). Incrustar, escrutinar e inscrever são alguns dos verbos que acionam a forma pateriana desse ensaio de cunho assumidamente nietzscheano.

Acerca desse cunho filosófico, torna-se imperativo que façamos uma leitura sincrônica desse ensaio sobre Pater com outro: "Qualquer dia, um centauro". Nesse texto "em torno de um livro impossível de F. Nietzsche", o poeta e professor Alberto Pucheu lê, em um Nietzsche finissecular, o nascimento de outras formas de pensar que investigam as historiografias literária e filosófica produzidas pela cultura ocidental. Nessa leitura que rompe com a noção de gênero, o filósofo faz convergir, de modo 
potencializado, as formas e forças das artes e da filosofia, sendo ressaltada a importância dos gregos e de sua porção dionisíaca para a compreensão da modernidade.

A potencialização dessas formas e forças remete à estetização existencial sugerida pelo ensaio sobre Pater. Na leitura que Latuf empreende da obra do escritor inglês, a estética é lida como "ciência autônoma da sensibilidade" em um texto em que a biografia e a bibliografia do referido autor dialogam, sugerindo ser Pater um dos padroeiros do decadentismo isso não é pouco se pensarmos no elenco de autores que sedimentam a referida estética, cujo altar abriga eleitos do porte de Poe, Baudelaire e Wilde. A estetização febril anunciada no título do texto aponta para a importância do ensaio e da poesia na construção dessa escrita: "no coração do crítico Pater adormecia um poeta que eclodia quando... (o autor) interrogava os outros artistas". Dessa leitura do texto pateriano resulta ainda a lição esteticista de repúdio a toda moral.

\section{II}

No ensaio “As 'roupagens' estéticas dos ensaios prazianos", a ensaísta Flora de Paoli lê um narrador-ensaísta a partir do texto do escritor italiano Mario Praz. Essa leitura tem na forma do ensaio o "instrumento ideal para dar vazão ao imaginário decadentista”, além de ressaltar a sintonia entre o eu que ensaia e o seu objeto, a confissão sugerida em toda crítica, e as relações entre a cidade e a escrita. Nessa leitura labiríntica, o excesso surge como um dos "personagens" principais dos cenários decadentistas, e o mais interessante é que o discurso ensaístico se constrói não apenas a serviço da descrição, mas principalmente com o objetivo de articular procedimentos textuais.

Produtor antigo de texto e espaços labirínticos, cabe ao poeta e professor Fernando Fiorese ensaiar sua cota de subjetividade maquínica. Em seu texto, a máquina ganha dimensão livresca, cuja ação prolonga e adapta "o corpo para acolher o mundo". Nessa acolhida, o poeta, o ensaísta e sua porção imaginária possuem papéis relevantes, uma vez que o caráter automático e repetitivo da máquina sugere a necessidade de o sujeito contemporâneo aumentar sua cota de invenção. Para isso, o autor opera, entre outras, a seguinte proposição: "desvelar a dimensão imaginária e a margem de indeterminação que toda máquina dissimula”. Nessa relação entre máquinas e páginas, Fiorese conecta Kant, Benjamin, Barthes e Mallarmé, concluindo o ensaio com um belo poema de seu livro Corpo portátil, cujo primeiro verso diz: "Livro só existe no plural".

Grávido de senhas para o leitor que se atreve a eleger o não dito como objeto do pensar é o texto conciso de Stella Ferreira. Ao ler "a ver- 
tigem labiríntica como ritual de iniciação", a autora nos induz a refletir acerca dos grandes estetas como criadores que, a exemplo de Oscar Wilde, alimentam o imaginário de seu tempo. Outra importante contribuição desse ensaio é o fato de ele possibilitar a tessitura de relações entre a máscara e o significante, ou seja, o texto de Stella faz pensar que a máscara - e não o que ela oculta - está para a construção identitária do sujeito assim como o significante - e não apenas o tema - está para a produção da linguagem literária, para a construção do texto estético.

Didático e dialógico, corpus de ponta, é o tex to de Luciana Salles. Centrada na tradição oral, ela consegue seu intento de sincronizar Oscar Wilde, João do Rio, Horacio Quiroga e a "literatura infantil para adultos", ressaltando as peculiaridades inerentes a cada um desses autores. Apesar da forma metalingüística desse estudo, que começa com o clássico “Era uma vez...", é recomendável, em uma próxima edição, que a autora reveja um ou dois jargões do texto, e solucione os problemas de ordem técnica da bibliografia.

\section{III}

O labirinto finissecular e as idéias do esteta reflete, em suas múltiplas máscaras e rubricas, e na polifonia de suas referências artísticas e culturais, uma marca singular em relação a seu corpus. É a singularidade desse corpus, os roteiros de cada um dos ensaios e as miríades de conexões por eles viabilizadas que pluralizam a leitura desse labirinto de letras. A grande maioria dos ensaios recorta um universo teórico e estético relativo a autores decadentistas e finisseculares. Nesse recorte singular, alguns estetas são visivelmente mais ensaiados. São os casos de Oscar Wilde, Walter Benjamin e Roland Barthes, que compõem o trio de autores mais relidos no livro em questão.

A vida à margem e a escrita decadentista de Oscar Wilde erigem grande parte dessa forma labiríntica. O esteta inglês surge como "ator" do teatro esteticista no ensaio do professor Latuf Isaías; depois o escritor aparece como componente da bibliografia de Mônica Fagundes e como tema central do ensaio de Stella Ferreira: "Oscar Wilde: o esteta e os mascaramentos do corpo". O autor de O príncipe feliz e outros contos é ainda um dos objetos da leitura de Luciana Salles e surge como precursor da modernidade na escrita de Samuel Abrantes, que analisa, à luz do "sistema" barthesiano, arte e moda no fim do século XIX, demonstrando como a última patrocina mutações corporais.

Além de "atuar" na longa epígrafe do ensaio de Rogério Lima que tematiza o "baixo valor do diálogo" no cenário pós-11 de setembro, Walter Benjamin serve de base para a leitura do tempo sincrônico empreendida por Mônica Fagundes ao traçar "Uma breve história do labirinto", que ostenta a mais labiríntica epígrafe do volume: "Perder-se também é caminho" 
(Clarice Lispector). Também as relações entre leitura e infância são tecidas por Luciana Salles a partir da tessitura de idéias benjaminianas. Para ler a narrativa italiana de "Luigi Malerba e as circulações da escrita decadentista", Sonia Reis recorre às Obras completas do pensador alemão, assim como Fernando Fiorese, que lê no autor de Rua de mão única a profecia da experiência do objeto livro para além do suporte material.

Roland Barthes "encena" o texto final. Referendado em outros ensaios do volume, principalmente no texto certeiro de Samuel Abrantes, o esteta francês surge como personagem principal de "Formas e truques de um écrivain-dandy”, escrito por Luiz Edmundo. A partir da leitura dos 16 fragmentos de "Soirées de Paris" (Incidentes), o ensaísta traça intertextos com a bibliografia do escritor francês, atentando para a audição dos ecos de, entre outros, Gide, Proust, Sade e Pascal na escrita barthesiana. Com base nisso, Luiz Edmundo inscreve um écrivain-dandy que rompe com a noção de gêneros (artísticos e sexuais), em um texto em que as simulações romanescas dão o tom. Ouçamos o ensaísta: "Se, para coroar o esteticismo fin-de-siècle, o dandy decadentista procurou realizar a beleza por meio de sua obra, coube ao écrivain-dandy tramar no ato de escrever sua possibilidade de existir".

Essa "trama" é visível no corpus que compõe $O$ labirinto finissecular e as idéias do esteta. Pater, Praz, Mallarmé, Visconti, Freud, Nietzsche, Sciascia, Malerba, Wilde, João do Rio, Quiroga, Bataille, Benjamin, Barthes... As idéias desses estetas, dândis e decadentistas se voltam, geralmente, para uma estetização existencial em que o texto da vida tem muito a ver com o texto da página. Na leitura dos móveis e objetos que os circundam, na inscrição de cidades e páginas que os acolhem, nos modos de ler as modas, na forma de estetizar os alimentos e corpos consumidos e mascarados... Tudo nesse corpus parece estetizado sob as bênçãos de Eros e as espetadas de Tânatos. Se possível, com a boa cota de ócio que toda criação requer. Para que haja sempre $O$ labirinto finissecular e as idéias do esteta e a letra não se apague.

Nonato Gurgel

Pesquisador do PACC.UFRJ

Professor da UNIGRANRIO 